\title{
DESENVOLVIMENTO DA ASSISTÊNCIA MÉDICA E DE ENFERMAGEM AOS DOENTES MENTAIS NO BRASIL: OS DISCURSOS FUNDADORES DO HOSPÍCIO
}

\author{
Maria Angélica de Almeida Peres ${ }^{1}$, Ieda de Alencar Barreira ${ }^{2}$
}

\begin{abstract}
${ }^{1}$ Doutora em História da Enfermagem. Professor Adjunto da Escola de Enfermagem Anna Nery (EEAN) da Universidade Federal do Rio de Janeiro (UFRJ). Rio de Janeiro, Brasil. E-mail: angelica.psi@uol.com.br

${ }^{2}$ Doutora em História da Enfermagem. Professora Titular aposentada, pertencente ao Quadro Permanente da Pós-Graduação da EEAN/UFRJ. Pesquisadora do CNPq 1A. Rio de Janeiro, Brasil. E-mail: iedabarreira@openlink.com.br
\end{abstract}

RESUMO: O estudo trata do Hospício de Pedro II como locus de desenvolvimento de saberes e práticas médicas e de enfermagem no Brasil Imperial. Pesquisa histórico-social cujos objetivos são identificar os discursos fundadores do Hospício de Pedro II e analisar a sua importância para a enfermagem pré-profissional no Brasil. Os dados foram provenientes de fontes primárias e secundárias, analisadas segundo os conceitos de Michel Foucault. Quatro discursos estiveram presentes na criação do hospício no Brasil: o discurso da filantropia, representado pela Santa Casa de Misericórdia, o discurso da caridade representado pelas Irmãs de Caridade, o discurso alienista representado pelos médicos dedicados ao estudo da loucura e o discurso do Estado Imperial, representado pelo Imperador D. Pedro II, todos de origem européia. A união desses discursos, embora com interesses distintos, foi responsável pela criação do primeiro hospício e pelo início da assistência médica e de enfermagem aos doentes mentais no Brasil.

DESCRIPTORES: História da enfermagem. Enfermagem psiquiátrica. Psiquiatria

\section{DEVELOPMENT OF MENTALLY ILL PATIENT MEDICAL AND NURSING CARE IN BRAZIL: THE FOUNDING DIALOGUES FOR ASYLUMS}

\begin{abstract}
The study concerns Pedro II’s Asylum as the locus of the development of knowledge and medical and nursing practices in Imperial Brazil. The aim of this historical-social research is to identify the founding speeches of Pedro II's Asylum and analyze their importance for pre-professional nursing in Brazil. The data were derived from primary and secondary sources and analyzed according to Michel Foucault's concepts. Four speeches were present in the creation of Pedro II's Asylum: the philanthropy speech, represented by Santa Casa da Misericórdia; the charity speech, represented by the Sisters of Charity; the psychiatrist speech, represented by physician dedicated to the study of madness; and the Imperial State speech, represented by Emperor D. Pedro II, all of European origin. Although having different interests, the union of those speeches was responsible for the creation of the first asylum and the beginning of medical and nursing assistance for Brazilian mentally ill patients.
\end{abstract}

DESCRIPTORS: History of nursing. Psychiatric nursing. Psychiatry.

\section{EL DESARROLLO DE LA ATENCIÓN MÉDICA Y DE ENFERMERÍA PARA ENFERMOS MENTALES EN BRASIL: LOS DISCURSOS FUNDADORES DEL HOSPICIO}

RESUMEN: La presente investigación trata sobre el Hospicio de Pedro II como locus de desarrollo de conocimientos y prácticas médicas y de enfermería en el Brasil Imperial. Es un estudio socio-histórico, cuyos objetivos son: identificar los discursos de los fundadores del Hospicio de Pedro II y analizar su importancia para la enfermería preprofesional en Brasil. Las fuentes primarias y secundarias, analizadas según los conceptos de Michel Foucault, mostraron la presencia de cuatro discursos en la creación de ese hospicio: el discurso de la filantropía, representado por la Santa Casa de Misericordia; el de la caridad, por las Hermanas de la Caridad; el de psiquiatría, por los médicos dedicados al estudio de la locura; y el del Estado Imperial, por el Emperador D. Pedro II, todos de origen europeo. La unión de estos discursos, aunque con diferentes intereses, fue responsable por la creación del primer hospicio y por el inicio de la atención médica y de enfermería para enfermos mentales en Brasil.

DESCRIPTORES: Historia de la enfermería. Enfermería psiquiátrica. Psiquiatría 


\section{INTRODUÇÃO}

O presente estudo tem como objeto o Hospício de Pedro II (HPII) como locus do desenvolvimento de saberes e práticas médicas e de enfermagem no Brasil Imperial. Criado em 1841, na capital do Império, o HPII visava à guarda e tratamento dos doentes mentais, sendo o primeiro hospital psiquiátrico da América Latina. Até a criação do HPII, embora ocorresse a internação de doentes mentais considerados perigosos no Hospital Geral da Santa Casa de Misericórdia, esses doentes não recebiam assistência médica nem de enfermagem, tendo a internação apenas o papel de exclusão social.

O movimento para a criação de um local específico para abrigar a loucura no Brasil, nos moldes daqueles existentes na França, iniciou-se na década de 30 do século XIX, envolvendo diferentes instituições como a Santa Casa de Misericórdia (SCM), oriunda de Portugal, a Congregação das Filhas da Caridade de São Vicente de Paulo e a medicina alienista, ambas de origem francesa, e o Estado Imperial, influenciado pela França e por Portugal em seu projeto civilizador da sociedade brasileira, no qual se inseriu a criação de um hospício para alienados.

O Decreto 82-A/1841, que criou o HPII, o anexava à SCM do Rio de Janeiro, que seria responsável por sua construção e administração. $\mathrm{O}$ suntuoso prédio, localizado na Praia da Saudade, atual Praia Vermelha, que daria lugar ao hospício, só veio a ser inaugurado em 1852 , ainda inacabado. Essa instituição tinha uma enorme importância política e financeira na sociedade do Rio de Janeiro: em primeiro lugar, o hospício, destinado à guarda dos loucos, tinha o propósito mais geral de combater a desordem, a mendicância e a ociosidade, que eram considerados fatores de perturbação da paz social e obstáculos ao progresso no século XIX; em segundo lugar, como unidade anexa à SCM, trazia vantagens de ordem política e financeira para a mesma; em terceiro lugar, o HPII apresentava um ambiente propício ao desenvolvimento de uma ciência própria da loucura, a partir do nascente saber sobre as doenças mentais.

Embora a criação do HPII tenha resultado da convergência de diferentes discursos, após a sua inauguração, os diferentes interesses das instituições envolvidas geraram conflitos referentes à sua administração e que se estenderam ao longo da segunda metade do século XIX. Os objetivos deste estudo são: identificar os discursos fundadores do HPII e analisar a sua importância para a enfermagem pré-profissional no Brasil.

\section{METODOLOGIA}

Estudo qualitativo de natureza históricosocial, cujas fontes primárias foram documentos escritos (leis, regulamentos, discursos, relatórios, atas e artigos de jornais) selecionados nos acervos da SCM, da Biblioteca Nacional e do Instituto Histórico e Geográfico do Brasil, todos localizados na cidade do Rio de Janeiro. As fontes secundárias foram livros, teses e estudos referentes à História da Enfermagem e da Psiquiatria no Brasil, à História das práticas de saúde no Brasil e à História do Brasil.

O referencial teórico foi o pensamento de Michel Foucault, que possibilitou analisar os diferentes discursos envolvidos na criação do hospício no Brasil e elucidar estratégias desenvolvidas pelos atores sociais presentes. Em seus textos, Foucault aciona toda uma gama de conceitos e noções que remetem a uma compreensão crítica das relações de poder e das práticas discursivas e não-discursivas que as sustentam, possibilitando pensar a história e as sociedades em termos de relações, tensões e conflitos. ${ }^{1} \mathrm{O}$ sentido atribuído por Foucault ao discurso não é o de teorias ou abstrações, mas de práticas, que apresentam uma materialidade e cuja formação se relaciona, necessariamente, com a formação no nível não-discursivo.

Os dados foram organizados e analisados de acordo com a temática e com a ordem cronológica dos acontecimentos, destacando os principais discursos envolvidos com a criação do hospício no Brasil.

\section{RESULTADOS E DISCUSSÃO}

\section{O discurso da filantropia: a Irmandade da Misericórdia e as Santas Casas}

A filantropia pode ser concebida a partir da idéia cristã de salvação e como uma resposta a uma demanda social, bem como uma política dos ricos e como forma de poder. Sendo assim, a participação dos filantropos se dá através de doações e legados, de loterias, de bailes beneficentes, de sermões religiosos, ou outra forma de auxílio aos necessitados, o que faz da filantropia um assunto de ricos. O Brasil herdou a tradição católica de socorro à pobreza, baseada nas ações pias da Igreja católica e, no caso da colonização portuguesa, nos trabalhos da SCM. ${ }^{2}$

A SCM foi fundada em Portugal, no final do século XV para socorrer a todos e quaisquer infelizes, pobres ou desamparados, enfermos, órfãos, viúvas e sentenciados, sem distinção alguma. 
Seu caráter de Irmandade ou Confraria se dá pelo princípio de socorrer os necessitados em hospitais, hospícios, asilos, orfanatos, etc., fundados ou administrados por ela, atendendo ao alívio de seus males físicos e espirituais, oferecendo ainda, conforto através da assistência religiosa. As Irmandades de Misericórdia são associações religiosas mistas, por possuírem um duplo caráter, espiritual e temporal, dependendo a parte espiritual das autoridades eclesiásticas e a parte temporal das autoridades civis. Na Misericórdia predominam os fins de caráter temporal (objetivo de assistência pública, função assistencial do Estado). ${ }^{3}$

A SCM do Rio de Janeiro surgiu em meados do século XVI, tendo como fundadores os primeiros povoadores portugueses, auxiliados pelo jesuíta José de Anchieta. ${ }^{3}$ A ausência de participação do Estado no campo da assistência médica nos primeiros anos do Império permitiu que a SCM agisse com quase exclusividade na viabilização do acesso da população ao tratamento médico-hospitalar no Rio de Janeiro. Porém, no século XIX inicia-se no Brasil uma transformação política e econômica que vai fazer a medicina intervir na sociedade, a fim de favorecer o poder do Estado. O aumento da população e um projeto de saneamento vão estreitar as relações entre a medicina e o controle do espaço urbano, no qual a presença de loucos, mendigos, criminosos, indigentes tornava-se cada vez mais indesejável, fazendo com que aqueles que outrora perambulavam pelas ruas, agora fossem trancados no Hospital Geral da SCM e nas cadeias públicas. ${ }^{4}$

No entanto, a simples segregação do louco não atendia aos desígnios da sociedade, pois o Hospital Geral da SCM não poderia comportar "todos os desviantes, que neste momento não podem mais ser tolerados na paisagem urbana",5:25 além disso, aquele local, devido às suas condições extremamente insalubres, não era considerado adequado à presença do médico, para que ele ali desenvolvesse atividades de estudo e tratamento. ${ }^{5}$

Por isto, no ano de 1830, a Sociedade de Medicina do Rio de Janeiro lançou uma campanha em favor da construção de um edifício específico, para abrigar a loucura. Neste sentido, a Comissão Geral de Salubridade dessa Sociedade, considerava uma ameaça à ordem urbana e um fato preocupante para a higiene pública, a livre circulação dos loucos pelas ruas da cidade. A Comissão também denunciava os maus tratos sofridos pelos mesmos, nas enfermarias do Hospital Geral da SCM. ${ }^{5}$

A essas condenações da Sociedade de Medicina do Rio de Janeiro somou-se a voz do Provedor
Geral da SCM, José Clemente Pereira que, como ministro e conselheiro do Império, ao assumir este cargo, em 1838, destacou a aliança da Irmandade com o Imperador e com a Faculdade de Medicina. Clemente Pereira desejava adequar os prédios da SCM às novas noções de higiene e planejamento exigidas pela Secretaria de Estado dos Negócios do Império. Tais exigências estavam contidas no relatório de 1824, da Sociedade de Medicina do Rio de Janeiro, que indicara as bases higiênicas para o planejamento da construção de estabelecimentos de saúde. Considerando estas novas bases, foi instituída em 1830, uma Comissão de conservação e melhoramentos da SCM do Rio de Janeiro, que produziu um relatório sobre o estado em que se encontravam as suas diversas repartições. ${ }^{6}$

Tal relatório apontava, dentre as necessidades do Hospital Geral, a retirada da enfermaria dos loucos do andar térreo. A alegação para esta medida era a de que estes incomodavam os doentes das demais clínicas, que se convalesciam nos andares superiores; além disso, os loucos eram alvo de escárnio pelas pessoas que transitavam na rua e nas passagens públicas que recortavam os espaços. O relatório também denunciava os maus tratos sofridos pelos doentes mentais, enfatizando a necessidade de dar-lhes tratamento adequado, segundo as teorias e técnicas já em prática na Europa, apontando a necessidade de criação de um espaço específico para abrigá-los. ${ }^{6}$

José Clemente Pereira, em 1839, relatou à Mesa e Junta da Santa Casa, que a situação dos alienados no Hospital Geral era de confinamento em pequenos quartos, considerando pior a situação das mulheres alienadas, definida por ele como deplorável. O Provedor destacou a necessidade de construção de um hospício de alienados na capital imperial, para a qual a SCM estava arrecadando dinheiro. ${ }^{7}$

No mesmo ano, Luiz Vicente de Simoni, médico da SCM e membro da Sociedade de Medicina do Rio de Janeiro, publica um artigo onde descreve detalhadamente as instalações dos loucos no Hospital Geral SCM, definida por ele como insuportável e demonstra ainda o apoio da Sociedade de Medicina do Rio de Janeiro à mesma, no que tange à criação de um hospício de alienados: "A esses brados nós vamos ajuntar os nossos, e ao quadro apenas esboçado pelo Sr. Provedor José Clemente Pereira no seu excelente relatório, acrescentar alguns traços para que o horror da desgraça do alienado nessa casa e neste país, e o perigo de nós todos se tornem tão vivos e tão salientes quanto 
requer a indiferença e a inação, que infelizmente tem havido entre nós a este respeito" . 5:245-51

Tão grave como o problema das instalações era o tratamento dispensado aos doentes. A SCM encarregava alternadamente dois médicos, cada um por seis meses do ano, de fazer visitas às repartições onde ficavam os alienados, não sendo estes dedicados ao estudo das moléstias mentais. No que se refere à enfermagem, a situação era caótica: os enfermeiros dos alienados eram escolhidos entre os existentes na casa, tirados ordinariamente das classes menos instruídas, em número tão pequeno, que se tornava difícil achar um que reunisse "todas as qualidades que se requerem em um enfermeiro de alienados. .:255

O artigo do Dr. Simoni fortalecia o discurso tanto da Sociedade de Medicina do Rio de Janeiro como o da SCM, para a criação de um hospício de alienados. Apoiado pelo discurso médico, o Provedor, em seu relatório relativo à gestão 1839-1840, manifestou o desejo de transformar em hospício de alienados a Chácara do Vigário Geral, pertencente à SCM, que neste momento já abrigava uma enfermaria de doentes mentais, em virtude da falta de espaço no seu Hospital Geral. ${ }^{5}$ Sendo assim, o Provedor enviou ofício ao Imperador D. Pedro II, oferecendo o terreno e sugerindo a compra de uma casa que ficava ao lado, para que se pudesse ter a área necessária para a construção de um hospício de alienados, e completou: "E porque, em tais fundações, a construção do edifício é pouco em comparação da despesa ordinária para sustento dos estabelecimentos, a SCM não terá dúvida em tomar esta a seu cargo, uma vez que se lhe confie a administração, como será de razão e até conveniente, pois oferecerá o terreno e a subsistência futura do novo hospital" . 8:288

A proposta da SCM foi aceita pelo Imperador e a criação do primeiro hospício de alienados no Brasil pode ser vista simbolicamente como um coroamento do nascente Império brasileiro, tendo em vista que, a assinatura do decreto correspondente foi um dos atos que solenizaram a coroação do Imperador menino Pedro II, denominando-o Hospício de Pedro II. Tal decreto foi assinado a 13 de julho de 1841, no dia da coroação. ${ }^{11}$

\section{O discurso da caridade: as Irmãs de Caridade de São Vicente de Paulo}

A origem e o significado das palavras filantropia e caridade são distintas, pois, enquanto a caridade é a virtude cristã, que além de levar a amar a Deus sobre todas as coisas, leva a amar o próximo como a nós mesmos, a filantropia é o sentimento que nos leva a ajudar os homens porque são seres da nossa espécie. ${ }^{2}$ Não obstante, embora a caridade cristã, como discurso fundador do HPII, estivesse associada ao discurso da filantropia da SCM, ela foi mediada pelas Irmãs de Caridade de São Vicente de Paulo, durante a implantação e consolidação desta instituição asilar.

A Congregação das Filhas da Caridade de São Vicente de Paulo, servas dos pobres, de vida apostólica e comunitária, foi fundada em Paris, no ano de 1633, por Vicente de Paulo, sacerdote francês, junto com a devota Luiza de Marillac, viúva rica, que se dedicava a ajudar os pobres. As Filhas da Caridade, também chamadas de Irmãs de Caridade, cuidavam daqueles que estavam excluídos da sociedade e procuravam fazer com que os nobres ouvissem o lamento dos pobres, zelando pelo respeito e dignidade de todo ser humano. ${ }^{9}$

As Irmãs de Caridade chegaram ao Rio de Janeiro em 1852, provenientes da França, após uma negociação entre o Provedor José Clemente Pereira e a Legação Imperial do Brasil em Paris, por intermédio do Comendador João Marques Lisboa, que resultou no Tratado firmado em Paris, em 21 de setembro de 1852, que estabelecia as obrigações recíprocas entre a SCM e as Irmãs de Caridade de São Vicente de Paulo. ${ }^{10}$

A negociação com a Ordem Vicentina de Paris, no ano da inauguração do Novo Hospital Geral da SCM e do HPII, contratava Irmãs de Caridade para se encarregarem dos serviços hospitalares. O modelo religioso de enfermagem, trazido pelas Irmãs de Caridade, era por elas aplicado há pelo menos três séculos em vários países. Elas atuavam auxiliando os médicos nos serviços de enfermaria e de economato, podendo também ser encarregadas do laboratório e da farmácia. O Tratado determinava que as Irmãs fossem encarregadas do serviço interno do Hospital Geral, do HPII e das enfermarias externas da SCM. ${ }^{10}$

O Tratado também determinava que as Irmãs de Caridade ficassem subordinadas, no que tange às relações temporais, ao Provedor e à Mesa da SCM, estando sujeitas às leis, decretos, ordens e regulamentos que regiam a administração do estabelecimento. Quanto ao número de Irmãs, este ficaria sujeito às exigências do serviço, sendo primeiramente fixado em trinta podendo chegar a sessenta. Dizia ainda que o Tratado era um instrumento normativo superior ao Regimento Interno do hospital, no que tange ao comportamento e atribuições das Irmãs de Caridade. ${ }^{10}$ 
Tanto o Hospital Geral quanto o HPII teriam uma Irmã Superiora responsável pela direção e coordenação de todo o trabalho interno. O estabelecimento tinha que oferecer às Irmãs uma residência separada e na proximidade do serviço, composta de um ou mais dormitórios, uma enfermaria, uma rouparia, um refeitório, uma sala de comunidade, um locutório, um gabinete para a Superiora e um oratório. O pagamento das Irmãs de Caridade ficou estipulado em 400 francos anuais para a conservação de vestuário. Quando doentes, as Irmãs deveriam ser mantidas e tratadas no estabelecimento, sendo suspensa sua gratificação; em caso de falecimento seriam enterradas às custas da SCM. ${ }^{10}$

No HPII, Irmãs de Caridade ficaram responsáveis pelo economato (cozinha, refeitório, lavanderia e rouparia), pelas enfermarias masculina e feminina, incluindo o serviço de enfermagem, pela farmácia e pelas oficinas de trabalho dos doentes. Como ajudantes das Irmãs de Caridade atuavam negros escravos ou libertos, imigrantes e meninas pertencentes ao Asilo de Órfãs da SCM. ${ }^{11}$

Com a chegada das Irmãs de Caridade ao hospício, o discurso da caridade vai servir aos interesses da SCM, com base no Regimento Interno do HPII, aprovado pela Mesa e Junta da SCM no ano de 1858, que dava a Irmã Superiora a direção do serviço econômico e das enfermarias. Como as enfermarias faziam parte do serviço sanitário, dirigido por um médico, este não tinha o controle total do serviço a ele subordinado. Além disso, as religiosas, ao contrário dos médicos, tinham acesso direto ao Provedor da SCM.

A prática das Irmãs de Caridade tinha como base, um saber dominado pela Congregação Vicentina e, historicamente construído em sua prática cotidiana nos hospitais franceses, o que associado ao incipiente saber médico sobre as doenças mentais, permitiu o domínio do espaço psiquiátrico pelas religiosas por 38 anos consecutivos. ${ }^{11}$

Dessa forma, a assistência de enfermagem pré-profissional aos doentes mentais no Brasil, se configurou a partir de um modelo religioso, trazido da França, e que vai servir aos interesses da SCM, ao invés de servir aos interesses médicos.

\section{O discurso acadêmico: os alienistas}

O nascimento da medicina mental/alienismo tem como marco fundamental o ano de 1793, quando ocorreu o gesto emblemático de Philipp Pinel, libertando os alienados das correntes no
Hospital de Bicêtre na França, cena esta, imortalizada na iconografia. ${ }^{12}$

Na virada do século XVIII para o século XIX, começou a haver na medicina uma predominância do pensamento ligado à doutrina organicista e o pensamento psiquiátrico passou a ser fortemente influenciado pelo desenvolvimento da anatomia patológica, fazendo com que os alienistas buscassem as causas orgânicas da loucura e desenvolvessem procedimentos terapêuticos físicos e medicamentosos. Duas instituições francesas destacaram-se por desenvolver experiências e formas de tratamento médico e de enfermagem, que se difundiram da França para o resto da Europa: os hospitais de $\mathrm{La}$ Bicêtre e de Salpêtrière, nos arredores de Paris. ${ }^{12}$

Devido à experiência de muitas ordens religiosas com o tratamento da loucura, houve durante o nascimento da medicina mental francesa, uma grande discussão sobre até que ponto o tratamento moral pineliano não seria algo semelhante ou complementar ao consolo espiritual proposto pelas instituições religiosas. Os alienistas franceses, durante o século XIX, detiveram-se na busca do poder, através do saber da medicina mental, a fim de estender sua autoridade profissional, mediante a perseguição de objetivos seculares anticlericais. ${ }^{12}$

No Brasil, nas primeiras décadas do século XIX, as pessoas acometidas por uma doença mental, por mais estranhos e diferentes que fossem considerados seus hábitos, não foram impedidas de se incorporar ao dia-a-dia da cidade. Entretanto, as práticas de reclusão também estavam presentes, mesmo sem haver um estabelecimento específico para abrigar a loucura. Quando apresentavam comportamentos considerados perigosos, os loucos eram presos nas cadeias públicas ou recolhidos ao Hospital Geral da SCM. ${ }^{13}$

Em meados do século XIX, o discurso médico, através da Sociedade de Medicina do Rio de Janeiro e da Faculdade de Medicina, se levanta contra a presença de alienados nas ruas e nas enfermarias da SCM, iniciando o movimento para a criação do hospício no Brasil, como uma forma de transformar as questões referentes à alienação mental em responsabilidade médica. ${ }^{5}$

A prática institucional do alienismo no Brasil teve como marco inicial a criação do HPII, com a importação de conceitos teóricos franceses, que chegaram aqui com um certo atraso, se concretizando na famosa doutrina do tratamento moral. O hospício possibilitava a inserção do louco em um espaço social organizado e disciplinado, segundo as normas 
de higiene, a fim de permitir que a loucura fosse definida, explicada e tratada pela medicina. ${ }^{14}$

A crítica contra a situação dos loucos nas ruas e no Hospital Geral da SCM foi parte central da argumentação do discurso médico pela construção de um hospício. A idéia básica era de que a SCM não oferecia condições para abrigar medicamente e recuperar o louco. A assinatura do decreto para a criação do HPII, em 1841, foi a primeira vitória desse posicionamento médico. ${ }^{4}$ No entanto, a expectativa dos alienistas não veio a se concretizar naquele momento. Ao contrário, o provedor José Clemente Pereira conseguiu ampliar seu poder institucional, pela anexação do hospício à SCM. ${ }^{11}$

A inauguração do HPII só ocorreria onze anos depois, em 1852, no mesmo ano da inauguração do Novo Hospital Geral da SCM, após grandiosa obra, e da chegada à capital imperial das primeiras Irmãs de Caridade provenientes da França. A cerimônia de inauguração do HPII, na qual a fé, a filantropia e a ciência deram-se as mãos, contou com o discurso de José Clemente Pereira (Provedor da SCM), do Dr. José Martins da Cruz Jobim (Diretor da Faculdade de Medicina/RJ), e do Dr. Francisco de Paula Cândido (Presidente da Academia Imperial de Medicina). A linhagem arquitetônica do HPII fala das intenções e disposições de seus fundadores; o prédio era disposto em um enorme retângulo, compreendendo quatro grandes pátios internos, separados por um corpo central, que dividia as alas masculina e feminina. Havia apenas uma entrada, o que exprimia a perspectiva de isolar os internados do mundo exterior, reforçada pela má localização na Praia da Saudade, sítio relativamente afastado do centro da cidade. ${ }^{15}$

O princípio de vigilância, necessário às instituições religiosas, foi adotado na arquitetura do HPII, que possuía uma capela no seu corpo central. Para os médicos, o HPII deveria atender aos princípios do tratamento alienista, que também considerava importante a vigilância dos doentes. No entanto, as práticas religiosas inseridas na rotina do hospício, tornaram-se motivo de grande insatisfação por parte dos médicos.

\section{O discurso da modernidade: o Estado Impe- rial e o Palácio da Praia Vermelha}

A consolidação do Estado Monárquico durante o Segundo Reinado (1841-1889) tinha como pontos básicos o reforço da figura do Imperador, a restauração do poder Moderador e do Conselho de Estado, e um conjunto de normas que consti- tuíam o espírito do regime. A figura de D. Pedro II inspirava a simpatia popular, por combinar características de um monarca liberal, preocupado com o bem estar do povo, e de um intelectual dedicado, interessado no progresso do país, atento aos avanços da ciência, entendido em astronomia, botânica e ciências naturais. ${ }^{16}$

O Intercâmbio cultural entre o Império francês e o Império brasileiro trouxe para as elites intelectuais a influência da maçonaria e do positivismo, responsáveis por um evidente progresso do espírito científico, acompanhando idéias de desenvolvimento da ciência e tecnologia que impregnava a vida intelectual. ${ }^{16}$

A medicina, influenciada pela doutrina positivista, sofreu uma mudança em sua orientação teórico-filosófica, levando os médicos a se autoconceberem como responsáveis pela orientação e organização da nação, o que se afinava com as demandas de reordenação social que existiam por parte do Estado. ${ }^{4}$

O Império brasileiro buscava implementar novas práticas e instituições, e a medicina brasileira colocou-se a favor destas transformações, tornandose um corpo institucional que serviu de veículo para as aspirações de uma sociedade em transformação. O campo médico vai se consolidar, defendendo a moralização e o progresso da ordem social brasileira, num período de reordenação jurídico-institucional e de grande turbulência política. ${ }^{12}$

Para um Império que buscava a afirmação de um poder central forte, ávido de se mostrar em sintonia com a modernidade, representada pela civilização européia, construir um hospício de alienados, em consonância com o discurso da medicina mental francesa, seria mostrar-se moderno aos olhos europeus. No Brasil, o hospício não representou uma solução jurídica e institucional para a tutela dos loucos e sim a possibilidade de atender às necessidades de um país imperial, escravocrata, patriarcal e patrimonialista, onde a distinção entre o poder religioso e as instituições laicas do Estado ainda não ocorrera, ao contrário do ocorrido na Europa. ${ }^{12}$

OHPII foi construído segundo o modelo arquitetônico do hospício criado em Paris, pelos padres de São João de Deus, mas não foi só na arquitetura que se assemelhou ao antigo hospício parisiense, essa instituição, originalmente, também mantinha uma assistência religiosa para os alienados. ${ }^{14}$

Percebe-se, segundo os relatos da época, uma ambivalência em relação ao HPII. Por um lado, era visto como um grande palácio, que abrigava loucos perigosos e furiosos, tratados de forma 
violenta. Por outro, era visto como um exemplo de filantropia e caridade, onde os mesmos recebiam tratamento digno, que nunca antes lhes fora oferecido. ${ }^{11}$ Deste modo, o HPII foi descrito de diferentes formas, em vários momentos históricos. $\mathrm{Na}$ análise do relato de um pesquisador viajante sobre sua visita ao HPII, nota-se uma percepção extremamente otimista: "A surpresa de Agassiz completou-se na tarde repousante em que, entrando sem ser percebido, escadas acima, foi meditar sobre as harmonias da ciência e da fé na capela, onde enfermeiros, doentes pacíficos e Irmãs de Caridade rezavam em coro o rosário. Fala da ordem, do asseio, da distribuição de serviços, do aspecto louvável do estabelecimento e estende os olhos ávidos de paisagem às janelas que se abrem sobre o mar, emoldurando um retalho cintilante de crepúsculo tropical. Apreciável cultura, pensou o naturalista, esta que resolve o problema dos tresloucados, hospedando-os com ostensiva nobreza numa casa amena e limpa em cujo vestíbulo de mármore bicolor as estátuas de Esquirol e Pinel simbolizavam o gênio humanitário" . 15:83

Ao contrário, outra análise, feita por médico é contundente: "[...] no hospício, os médicos se transformaram em um instrumento de um poder situado fora do estabelecimento, de rejeição e de discriminação dos loucos, que eram ou poderiam ser terríveis, traiçoeiros e perigosos. Isso ainda era mais evidente, quando se tratava de um doente pobre. A vida lá dentro tornou-se caótica e o povo tremia só em ouvir falar a palavra hospício. E os transeuntes, passavam ao largo, apressados, para não verem ou ouvirem os loucos agarrados às grades de ferro, gritando e gesticulando" ${ }^{17: 24}$

A ênfase dada ao tratamento do doente pobre se justifica pela separação de classes no HPII, onde os doentes pagantes tinham tratamento diferenciado, de acordo com suas posses. Havia dois grandes refeitórios, um para pagantes, outro para indigentes e na parte superior do corpo central ficava a capela, em posição de destaque o que, em termos arquitetônicos, demonstrava a preponderância do caráter religioso, que imperava no hospício; havia ainda a farmácia, salões, bibliotecas e banhos. ${ }^{15}$

A ambição do Império brasileiro em assemelhar-se aos seus pares europeus deixava a configuração racial da população em evidência. Para integrar-se à modernidade, a negritude e a mestiçagem deveriam parecer questões sem importância. Assim, o "nababesco Hospício de Pedro II nasce com a missão de prestar atendimento a brancos e europeus residentes no Império, destinando uma pequena parte de seu funcionamento aos negros e mestiços e praticamente não atendendo aos escravos". ${ }^{12: 113-4}$

Se no espaço urbano a medicina podia intervir junto à população, no espaço institucional isto não lhe era permitido, devido ao modelo religioso nele implantado pelo próprio governo imperial, onde a Irmã Superiora, segundo o Regimento Interno do HPII, tinha uma posição hierárquica superior ao médico diretor do Serviço Sanitário. Ou seja, o mesmo governo que dava ao médico o poder de designar quem era louco e determinar sua internação, intervindo na organização do espaço social brasileiro, também o impedia de exercer o poder dentro do espaço institucional designado aos loucos na capital imperial. ${ }^{11}$

Dessa forma, o encontro dos médicos alienistas com as Irmãs de Caridade no espaço do HPII terminou por gerar um embate crescente entre o saber-poder religioso e o científico. Os diferentes interesses do Império brasileiro colocou de um lado o discurso caritativo-religioso, justificado pelo domínio da igreja nas instituições hospitalares, e de outro, o discurso médico, que buscava transformar a medicina mental em prática científica, com um mandato social de controle de sujeitos sociais desviantes. O propósito desse grupo de médicos vai se concretizar na luta pela desanexação do HPII da Santa Casa de Misericórdia do Rio de Janeiro, iniciada no início dos anos 80 e vitoriosa nos primeiros meses do governo republicano. ${ }^{11}$

\section{CONSIDERAÇÕES FINAIS}

Os resultados da pesquisa nos permitiram chegar aos discursos dos fundadores do HPII: o discurso da filantropia, representado pela Santa Casa de Misericórdia; o discurso da caridade, representado pelas Irmãs de Caridade; o discurso do alienismo, representado pelos médicos alienistas e o discurso da modernidade, representado pelo Estado Imperial.

A criação do HPII, em 1841, teve como base uma aliança circunstancial entre o Estado, a Santa Casa e os alienistas, onde interesses distintos estavam em jogo: ao primeiro demonstrar a sua beneficência e preclara visão; à segunda interessava ampliar seu poder político, institucional e financeiro, retirar os alienados do seu hospital-geral e livrar-se das denúncias e acusações proferidas publicamente pelos médicos; e aos terceiros, interessava a observação dos doentes para o desenvolvimento científico. 
A criação de um hospital de alienados no Brasil resultou de um importante movimento de mudança na sociedade, desencadeado pela união de discursos de origens diferentes, contra a segregação do louco no Hospital Geral da Santa Casa. Por iniciativa do Provedor da Santa Casa, José Clemente Pereira, apoiado pelo Imperador, deu-se início a assistência aos doentes mentais no Brasil, em 1852, a partir da inauguração do HPII e da vinda das Irmãs de Caridade para nele organizar a assistência de enfermagem e o serviço econômico.

O HPII foi o primeiro espaço onde se organizou uma assistência de enfermagem aos doentes mentais no Brasil e onde se desenvolveram saberes e práticas, liderados pelas Irmãs de Caridade, que constituem os primórdios da enfermagem psiquiátrica brasileira.

Durante os primeiros anos de funcionamento do HPII, o discurso da filantropia e da caridade foram consonantes, deixando o discurso científico sem segundo plano, situação que veio a se inverter nas últimas décadas do século XIX, quando os ideais positivistas passam a influenciar mais fortemente a sociedade brasileira.

Sendo assim, o HPII constituiu-se em uma instituição de grande significado histórico, onde se desenvolveram saberes e práticas, tanto médicas como de enfermagem, que ainda hoje, ao nos permitir esse olhar para o passado, contribui para o entendimento dos primórdios da psiquiatria no Brasil e nos leva a uma reflexão sobre a reorganização da assistência aos doentes mentais. Sua existência como Patrimônio Histórico nos remete ao Brasil Imperial e a memória preservada para as futuras gerações.

\section{REFERÊNCIAS}

1. Costa R, Souza SS, Ramos FRS, Padilha MICS. Foucault e sua utilização como referencial na produção científica em enfermagem. Texto Contexto Enferm. 2006 Out-Dez; 17(4):629-37.

2. Sanglard GP. Mecenato científico na virada do século carioca: exemplos e análises. In: Anais do XI Encontro Regional de História - Democracia e Conflito, 2004 Out 19-23; Rio de Janeiro (RJ): ANPUH; 2004.

3. Mourão C. Resposta em 22 de maio de 1949, ao ofício No 895 de 3 de maio de 1949. In: Santa Casa de Misericórdia do Rio de Janeiro. Rio de Janeiro (RJ): Diversos; 1949.

4. Machado R, Loureiro A, Luz R, Muricy K. Danação da norma: medicina social e constituição da psiquiatria no Brasil. Rio de Janeiro (RJ): Graal; 1978.

5. Simoni LV. Importância da criação de hum manicômio ou estabelecimento especial para o tratamento dos alienados. Revista Médica Fluminense. 1839; 6:241-62.

6. Santa Casa de Misericórdia do Rio de Janeiro. Ofícios da Comissão de conservação e melhoramentos da Santa Casa de Misericórdia do Rio de Janeiro. Rio de Janeiro (RJ): Santa Casa de Misericórdia documentação avulsa, 1824.

7. Extrato do Relatório do Provedor da Santa Casa de Misericórdia, com algumas notas. Revista Médica Fluminense. 1839; 6:262-271.

8. Lopes C. Primeiro hospital psiquiátrico no Brasil. Arq Neuro-Psiquiatr. 1935; XVIII (6):186-89.

9. Padilha MIC. Do cuidado da alma ao cuidado do corpo: uma nova compreensão da história da enfermagem. Rev Bras Enferm. 1998; 51(3):431-46.

10. Tratado entre a Santa Casa da Misericórdia da Corte e as irmãs de caridade (21/9/1852). Rio de Janeiro (RJ): Tipografia de Oliveira \& Companhia; 1881.

11. Peres MAAP. A ordem no hospício: primórdios da enfermagem psiquiátrica no Brasil (1852-1890) [tese]. Rio de Janeiro (RJ): Universidade Federal do Rio de Janeiro. Escola de Enfermagem Anna Nery. Programa de Pós-Graduação em Enfermagem; 2008.

12. Teixeira MOL. Deus e a ciência na terra do sol: o hospício de Pedro II e a constituição da medicina mental no Brasil [tese]. Rio de Janeiro (RJ): Universidade Federal do Rio de Janeiro. Escola de Enfermagem Anna Nery. Programa de PósGraduação em Enfermagem; 1998.

13. Engel MG. Os delírios da razão: médicos, loucos e hospícios (Rio de Janeiro, 1830 - 1930). Rio de Janeiro (RJ): Editora FIOCRUZ; 2001.

14. Lopes JL. A psiquiatria e o velho hospício. J Bras Psiquiatr. 1965; 14(1-2):117-30.

15. Calmon P. O palácio da Praia Vermelha. Rio de Janeiro (RJ): Ed. Universidade do Brasil; 2004.

16. Schwarcz LM. O espetáculo das raças. Cientistas, instituições e pensamento racial no Brasil: 1870-1930. São Paulo (SP): Companhia das Letras; 1993.

17. Arruda E. Síndrome de opressão: estudo antropológico existencial. Rio de Janeiro (RJ): Fundação Getúlio Vargas; 1966. 